\title{
Successful management of an Rh alloimmunised twin gestation pregnancy with multiple atypical antibodies with severe fetal anemia
}

\author{
Rakhi Sikarwar*, Meena Satia, Shruti Panchbudhe
}

Department of Obstetrics and Gynecology, Seth G S Medical college and KEM. Hospital, Mumbai, Maharashtra, India

Received: 06 June 2017

Accepted: 29 June 2017

*Correspondence:

Dr. Rakhi Sikarwar,

E-mail: drrakhisikarwarkem@gmail.com

Copyright: () the author(s), publisher and licensee Medip Academy. This is an open-access article distributed under the terms of the Creative Commons Attribution Non-Commercial License, which permits unrestricted non-commercial use, distribution, and reproduction in any medium, provided the original work is properly cited.

\begin{abstract}
Rhesus-D alloimmunization is characterized by production of antibodies as a result of immune response generated in an individual due to exposure to alloantibodies from different individual. Here we are reporting a case of successful obstetric and perinatal outcome of twin pregnancy with Rh-incompatibility along with other atypical antibodies leading to fetal and neonatal anemia in both the twins. Antenatal management consisted of serial obstetric Doppler to look for Middle cerebral artery blood flow and Peak systolic velocity to detect fetal anemia followed by Intra Uterine transfusion of packed red cells through umbilical vein to treat the same for both the twins. In the presence of multiple atypical antibodies in the maternal serum no compatible blood was available for transfusion for either the mother or the neonates after delivery so NICU management consisted initially of transfusion of intravenous immunoglobulin's along with steroids to prevent auto and alloantibody reactions but in view of dropping hemoglobin in both twins least incompatible blood was given to both the twins.
\end{abstract}

Keywords: Fetal anemia, Neonatal anemia, Rhesus-D alloimmunization, Twins

\section{INTRODUCTION}

Hemolytic disease of the fetus and newborn (HDN) is a condition in which hemolysis of fetal and neonatal RBC occurs due to maternal antibodies. Rh negative mothers develop antibodies due to alloimmunization during fetomaternal hemorrhage and blood transfusion against $\mathrm{Rh}$ positive fetus due to the Rhesus-D incompatibility. Other Rhesus antigens like $\mathrm{c}$ and $\mathrm{E}$, and antibodies against the Kell, Duffy and Kidd systems, are also important. ${ }^{1}$ Naturally occurring antibodies like anti-A, and anti-B, or those immune antibodies which develop after a sensitizing event, like feto-maternal hemorrhage and blood transfusion may also cause hemolytic disease resulting in severe anemia. ${ }^{2}$ With the use of $\mathrm{RhD}$ Immunoprophylaxis, the incidence of anti-D has decreased dramatically but other alloantibodies are now a major cause of HDN. ${ }^{3}$ The disease results when maternal $\underline{\text { antibodies }}$ to Kell antigen breach the placental barrier and reach the fetus across placenta. Very severe disease, hydrops foetalis may develop at as early as 20 weeks gestation. Detection of anti-Kell antibodies during antenatal period is an indication for referral of patient to a tertiary care center for further evaluation and management. We describe management of case of fetal hemolytic disease in case of $\mathrm{Rh}$ alloimmunisation with atypical antibodies like $\mathrm{c}, \mathrm{e}, \mathrm{Fy}^{\mathrm{a}}, \mathrm{Jk}^{\mathrm{b}}, \mathrm{P}^{1}$ as shown in Table 1 below. Presence of multiple antibodies in the maternal serum makes it difficult to arrange for compatible blood, hence surgical intervention also becomes very challenging.

\section{CASE REPORT}

A 27-year-old multigravida, a diagnosed case of $\mathrm{Rh}$ isoimmunisation along with atypical antibodies in the maternal serum presented with dichorionic diamniotic 
twin gestation at $34 \mathrm{wks}$ of gestation. She was referred to our institution with Doppler studies suggestive of fetal anemia in twin II for further management. Patients' blood group was A negative, her husband was $\mathrm{Rh}$ positive. She had received injection anti $\mathrm{D}$ in her previous pregnancies and there was no history of blood transfusion. During her present pregnancy, her Indirect Coombs Test titers were $1: 32$ at 22 weeks of gestation, Because of the presence of multiple antibodies in the maternal serum as shown in the table 1 below not even a single unit of crossed matched blood was available for her. In view of these reports and non-availability of compatible blood, she was referred to a higher center.

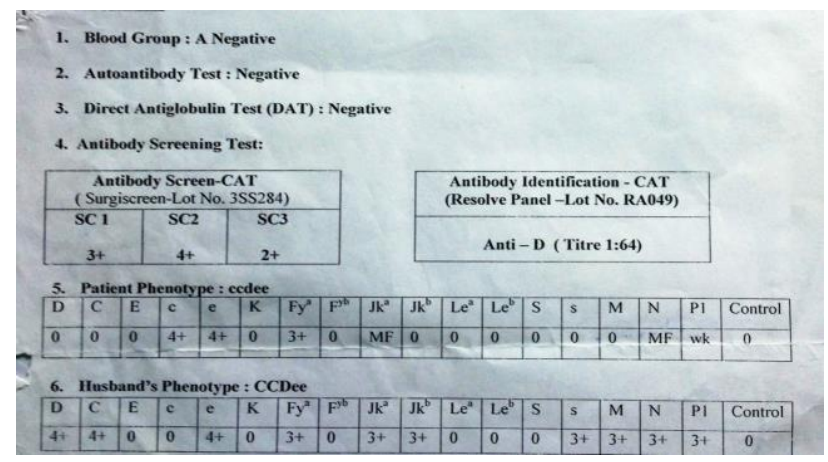

Figure 1: Blood report of patient showing multiple antibodies.

Patient was referred from a private institution where Color Doppler done at 29 wks was suggestive of fetal anemia in both fetus thus requiring intra uterine transfusion. Cord blood sampling was done after explaining all the risk and consequences to the patient and relatives and cross matched with donor blood bag. Both fetus's blood group was found to be Rh positive, and intrauterine blood transfusion was done by fetal medicine expert using $\mathrm{O} \mathrm{Rh}$ negative blood group. Prior to performing transfusion both the fetus had hemoglobin of 8 gram $\%$ which was risen to 11 grams $\%$ after intrauterine transfusion. Color Doppler was again repeated at 32 weeks which was suggestive of fetal anemia in second twin requiring delivery of fetuses. USG Obstetric Doppler was repeated which was suggestive of intrauterine growth restriction in both twins with raised S/D ratio with raised Middle cerebral artery peak systolic velocity suggestive of fetal anemia in twin II with no evidence of hydrops in both twins. Patient's blood was cross matched with both A negative and $\mathrm{O}$ negative blood but compatible blood was not available at all. All blood banks in the city were contacted but no compatible blood unit was found. Patient and relatives were explained about the need for induction of labor sos caesarean section and non-availability of compatible blood, its associated risk and complications were explained to them. A multidisciplinary team consisting of obstetrician, neonatologist, blood bank in-charge and transfusion medicine, where this case was discussed and it was decided that in case of utmost emergency the least incompatible blood will be given to the patient in case of life-saving situation after obtaining an informed consent from the patient and relatives. Elective lower segment caesarean section was done and patient delivered twins, first child female $2.29 \mathrm{~kg}$ and second child male $2.12 \mathrm{~kg}$. Babies were kept in NICU since birth. DCT was positive Hemoglobin was dropping and there was no compatible blood available for transfusion so they were given Intravenous Immunoglobulin as they decrease the need for blood transfusions, duration of phototherapy and duration of hospital stay. Daily Serum bilirubin and Hemoglobin levels were monitored both babies and both were kept under double surface phototherapy. Injection methyl-pednisolone was given to both babies for 3 days followed by Syrup Prednisolone in tapering doses to prevent auto and alloimmune reaction in babies. Hemolysis continued in first twin and hemoglobin dropped further to $4 \mathrm{gm} \%$ so baby was given blood which was least incompatible after taking proper consent. Second baby needed 2 blood transfusions in order to maintain hemoglobin above $10 \mathrm{gm} \%$. Oral feeds were started to both the babies, and both the babies gained weight. Post caesarean section mother was stable and luckily did not require any blood transfusion and was transferred to NICU on day 10 post-op to take of her neonates.

\section{DISCUSSION}

If an antigen is absent on red cell membrane of an individual, then they have corresponding anti-A and/or anti- B antibodies in the serum and these are called "naturally occurring" antibodies, (Example: anti-A in blood group $\mathrm{B}$, anti-B in blood group $\mathrm{A}$, anti-AB in blood group $\mathrm{O}$ ). In general, if the antigen is absent from the red cell, antibody against it is not produced normally in various blood group systems including the ABO. The production of such antibodies in these patients is called as unexpected or atypical or alloantibodies. ${ }^{4}$ Events such as blood transfusion or pregnancy results in production of such antibodies which are normally of IgG class example: anti-D, anti-C, anti Fy etc. There are almost 270 blood group antigens which are categorize into one of 26 blood group systems..$^{5}$ There are few more antigens which do not fall into these blood group systems. The Antibodies to all these antigens may or may not cause Hemolytic Transfusion Reaction.

Table 1: Name of the blood group and clinically significant antibodies.

\begin{tabular}{|ll|}
\hline $\begin{array}{l}\text { Name of blood group } \\
\text { system }\end{array}$ & $\begin{array}{l}\text { Clinically significant } \\
\text { antibodies }\end{array}$ \\
\hline ABO & A, B and AB \\
\hline Rh & $\mathrm{D}, \mathrm{C}, \mathrm{E}, \mathrm{c}, \mathrm{e}$ \\
\hline Duffy & $\mathrm{Fy}^{\mathrm{a}}, \mathrm{Fy}^{\mathrm{b}}$ \\
\hline Kidd & $\mathrm{Jk}^{\mathrm{a}}, \mathrm{Jk}^{\mathrm{b}}$ \\
\hline Kell & $\mathrm{K}$ \\
\hline MNS & $\mathrm{S}, \mathrm{s}$ (rarely M, N) \\
\hline Lewis & $\mathrm{Le}^{\mathrm{a}}($ rarely) \\
\hline
\end{tabular}


"A Compatible cross-match indicates that antibodies corresponding to the antigens of donor's red cells are absent in patient's serum/plasma. But a compatible crossmatch also may have atypical antibodies in patient's serum or plasma.

Any red cell antigen present on fetal cells and absent from the mother can stimulate antibody production in mother, the antigen that most frequently induces immunization is D. These antibodies can cross the placenta as these are of class $\mathrm{IgG}$ and may cause hemolysis of fetal red blood cells and caused HDFN. ${ }^{6}$

Depending on the specificity of the causative $\operatorname{IgG}$ antibody HDFN is often classified into three types. In descending order of potential severity, they are:

- D hemolytic disease. It is caused by anti-D antibody alone. In some cases, it may be caused by anti-C or anti-E, but it's rare.

- "Other" hemolytic disease. These are caused by antibodies against other antigens in the $\mathrm{Rh}$ system or against antigens in other systems; anti-c and anti-K are most often implicated.

- $\mathrm{ABO}$ HDFN. It caused by anti-A, B in a group O woman or by isolated anti-A or anti-B.

The samples of all pregnant women should be taken early in pregnancy ideally at the booking visit at 10- 16 weeks gestation for $\mathrm{ABO}$ and $\mathrm{D}$ typing and for screening for the presence of red cell alloantibodies. In patients who are tested positive for antibodies, should undergo further evaluation to determine their specificity and significance. All pregnant women irrespective of their D positive or D negative status, should have a repeat blood sample taken at 28 weeks gestation to re-check their ABO and D group and further screening for presence of red cell alloantibodies. In late pregnancy women are likely to form antibodies which are other than anti D irrespective of their $\mathrm{Rh}$ status. If red cell antibodies are detected, they should be further tested to determine the origin, concentration, specificity of antibodies.

Patient should also be evaluated for likelihood of HDFN. The most common antibodies implicated in causing hemolytic disease of new borne are Anti-D, anti-c and anti-K. The disease can be severe enough to warrant antenatal intervention as was seen in our case, and it becomes difficult to obtain compatible donor red cells for transfusion. Such women should attend pre-pregnancy counseling with a clinician who has knowledge and expertise in managing these conditions. ${ }^{7}$

Obstetricians managing these patients should be aware that severe fetal anemia can result in hydrops which worsens the perinatal outcome. Non-invasive fetal genotyping using maternal blood is now possible for $\mathrm{D}$, $\mathrm{C}$, c, E, e and $\mathrm{K}$ antigens. For other antigens, invasive testing like chorionic villus sampling (CVS) or amniocentesis may be considered if fetal anemia is a concern or if invasive testing is performed for another reason (e.g. karyotyping). Anti-D prophylaxis should be given to mother if $\mathrm{Rh}$ negative to cover invasive testing if she is not sensitized.

Consulation with a fetal medicine specialist should be done when there are rising antibody levels/titres, above a specific threshold or ultrasound features are suggestive of fetal anemia. Patient those who have a previous history of unexplained severe neonatal jaundice, transfusion or exchange transfusion required for neonatal anemia should also be referred to fetal medicine specialist, as they are at high risk of developing hemolytic disease of the fetus and newborn (HDFN). During antenatal period, the antibodies titers should be measured every 4 weeks up to 28 weeks of gestation and then every 2 weeks until delivery. The presence of antibodies that can potentially cause serious problems with the availability of appropriate blood for the women or the babies, a close collaboration with the blood transfusion service is necessary regarding the frequency of antenatal testing. If the fetus carries the corresponding antigen for maternal antibody which is capable of causing fetal anemia due to hemolysis, such patient should be monitored weekly by ultrasound, specifically assessing the fetal middle cerebral artery peak systolic velocities (MCA PSV). If the MCA PSV rises above the 1.5 times of the median (MoM) threshold or if there are signs of fetal anemia then intrauterine blood transfusion shoul be planned after consulting fetal medicine expert. ${ }^{8}$ Blood for Intra uterine transfusion should be of either of identical group, ABO of fetus or $\mathrm{O}$ (low titer haemolysin) and it should be absent for the antigen(s) corresponding to maternal red cell antibodies. As obtaining the relevant blood may take longer, maternity staff should liaise with their local transfusion laboratory to assess and plan for any possible transfusion requirements because of the antibodies other than anti-D, anti-c, anti-C, anti-E or anti-K. At least weekly cross match sample should be taken pregnant women with red cell antibodies, who are assessed as being at high risk of requiring blood transfusion. If maternal transfusion is required than Red cell components of the same $\mathrm{ABO}$ group and $\mathrm{Rh} \mathrm{D}$ type, and the selected blood should be negative for $\mathrm{K}$ antigen and cytomegalovirus (CMV) negative.

Anti D immunoglobulin should be given to all Rh antigen negative women as a routine antenatal prophylaxis or for potential antenatal sensitizing events and postnatal prophylaxis. If anti-D antibodies are detected, prophylaxis is no longer necessary. Management of such cases need close coordination among the maternity, neonatology and hematology staff. Finding a compatible blood is difficult for such patients, rare blood donors may need to be called up to donate blood, or frozen blood may need to be obtained from the National registries. These National registries of rare blood donor is lacking in India which led to difficulty in finding a suitable donor. For the babies, regular assessment of hemoglobin and serum bilirubin levels should be done to look for degree of 
hemolysis and need for blood transfusion or phototherapy hence early discharge is not advisable. Breast feeding should be encouraged in mother to prevent dehydration, as dehydration also contributes in the severity of jaundice. Phototherapy and/or exchange transfusion may be required if bilirubin levels rise rapidly or above the interventional threshold. Treating clinicians should be aware that in infant's anemia may persist for a few weeks following birth and some infants may develop late anemia.

No specific treatment is required in pregnancies complicated by red cell alloimmunization when there is minimal or no risk of fetal or neonatal anemia. A woman with a history of a pregnancy or infant affected by HDFN should have pre-conception counseling and should be referred to a fetal medicine specialist in all further pregnancies for early assessment.

Women should be counseled properly as there are no long-term adverse health consequences associated with the presence of red cell antibodies to avoid unnecessary anxiety. Suggestions have been made that women of child bearing age or young girls should not be given a transfusion with $\mathrm{Kell}_{1}$ positive blood. Kell antigen screening is not done on donated blood as it is not considered cost effective.

It has been hypothesized that sensitization of RBC to surface $\mathrm{Kell}_{1}$ antigen can be prevented by giving IgG anti-Kell $_{1}$ antibody injections in a similar way as IgG anti-D antibodies (Rho(D) Immune Globulin) prevent $\mathrm{Rh}$ alloimmunization, but the methods for IgG anti-Kell antibodies have not yet been developed.

Funding: No funding sources Conflict of interest: None declared Ethical approval: Not required

\section{REFERENCES}

1. Hadley AG. A comparison of in vitro tests for predicting the severity of haemolytic disease of the fetus and newborn. Vox Sang. 1998;74(Suppl 2):375-83.

2. Basu S, Kaur R, Kaur G. "Hemolytic disease of the fetus and newborn: Current trends and perspectives". Asian J Transfus Sci. 2011;5(1):3-7.

3. Cacciatore A, Rapiti S, Carrara S, Cavaliere A, Ermito S, Dinatale A, et al. Obstetric management in $\mathrm{Rh}$ alloimmunizated pregnancy. J Prenat Medic. 2009; (2):25-7.

4. Rippee C, Myers J, Gindy L. Blood groups, in Clinical Practice of Transfusion Medicine, $3^{\text {rd }}$ ed, edited by LD Petz, SN Swisher, S Kleinman, et al. Churchill Livingstone, New York; 1996.

5. Daniels GL, Human Blood Groups. Blackwell Scientific, Oxford; 1995.

6. Koenig JM, Christensen RD. Neutropenia and thrombocytopenia in infants with $\mathrm{Rh}$ hemolytic disease. J Pediatr. 1989;114(4.1): 625-31.

7. De Haas M, Thurik FF, Koelewijn JM, Van Der Schoot CE. Haemolytic disease of the fetus and newborn. VoxSanguinis. 2015;109(2):99-113.

8. Mari G, Deter RL, Carpenter RL, Rahman F, Zimmerman R, Moise KJ, et al. Collaborative Group for Doppler Assessment of the Blood Velocity in Anemic Fetuses. Noninvasive diagnosis by Doppler ultrasonography of fetal anemia due to maternal redcell alloimmunization. N Engl J Med. 2000;342:914.

Cite this article as: Sikarwar R, Satia M,

Panchbudhe S. Successful management of an Rh alloimmunised twin gestation pregnancy with multiple atypical antibodies with severe fetal anemia. Int J Reprod Contracept Obstet Gynecol 2017;6:3699-3702. 